\title{
Integration of AIN piezoelectric thin films on ultralow fatigue TiNiCu shape memory alloys
}

\author{
Sabrina M. Currtis ${ }^{1}$ (D) Niklas Wolff ${ }^{2}$, Duygu Dengiz ${ }^{3}$, Hanna Lewitz ${ }^{3}$, Justin Jetter ${ }^{3}$, \\ Lars Bumke ${ }^{3}$, Patrick Hayes ${ }^{3}$, Erdem Yarar $^{3}$, Lars Thormählen ${ }^{3}$, Lorenz Kienle ${ }^{2}$, \\ Dirk Meyners ${ }^{3}$, Eckhard Quandt ${ }^{3, a)}$ \\ ${ }^{1}$ Chair for Inorganic Functional Materials, Faculty of Engineering, Kiel University, Kiel 24143, Germany; and Department \\ of Materials Science and Engineering, University of Maryland, College Park, Maryland 20742, USA \\ ${ }^{2}$ Chair for Synthesis and Real Structure, Faculty of Engineering, Kiel University, Kiel 24143, Germany \\ ${ }^{3}$ Chair for Inorganic Functional Materials, Faculty of Engineering, Kiel University, Kiel 24143, Germany

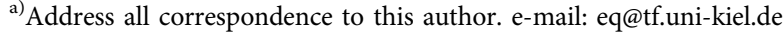 \\ This paper has been selected as an Invited Feature Paper. \\ Received: 24 December 2019; accepted: 7 April 2020
}

Biomagnetic field sensors based on AIN/FeCoSiB magnetoelectric (ME) composites desire a resonant frequency that can be precisely tuned to match the biomagnetic signal of interest. A tunable mechanical resonant frequency is achieved when ME composites are integrated onto shape memory alloy (SMA) thin films. Here, high-quality c-axis growth of AIN is obtained on (111) Pt seed layers on both amorphous and crystallized TiNiCu SMA thin films on Si substrates. These composites show large piezoelectric coefficients as high as $d_{33, \mathrm{f}}=6.4$ $\mathrm{pm} / \mathrm{V} \pm 0.2 \mathrm{pm} / \mathrm{V}$. Annealing the AIN/Pt/Ta/amorphous TiNiCu/Si composites to $700{ }^{\circ} \mathrm{C}$ to crystallize TiNiCu promoted interdiffusion of Ti into the Ta/Pt layers, leading to an enhanced conductivity in AIN. Depositing AIN onto already crystalline TiNiCu films with low surface roughness resulted in the best piezoelectric films and hence is found to be a more desirable processing route for ME composite applications.

\section{Introduction}

Thin-film magnetoelectric (ME) composites are attractive candidates for use in biomagnetic sensors, energy harvesters [1], highly efficient power converters, magnetometers, RF tunable inductors, and mechanical antennas [2, 3, 4, 5]. Heterostructures with aluminum nitride (AlN) serving as the piezoelectric layer and amorphous iron-cobalt silicon boron (FeCoSiB) alloy as the magnetostrictive layer have demonstrated ME coefficients in vacuum as large as $20 \mathrm{kV} / \mathrm{cm}$ Oe [6] with limits of detection as low as $1 \mathrm{pT} / \sqrt{\mathrm{Hz}}[6,7,8]$. The $\mathrm{ME}$ voltage and sensitivity can be enhanced by 1-2 orders of magnitude when driven at the mechanical resonant frequency $[3,9,10]$; therefore, many applications could benefit from a ME composite with a tunable resonant frequency. For example, deep brain stimulation (DBS) is a medical treatment used on patients suffering from tremors or dystonia. In this treatment, an array of electrodes are implanted deep in the patient's brain and stimulated at a well-defined frequency between 130 and $170 \mathrm{~Hz}$ [11]. For localization of the stimulated area near the electrode, it would be necessary to precisely tune the mechanical resonant frequency of a ME sensor to match the stimulation frequency of the electrode, or one of its multiples [11, 12, 13].

Nickel-titanium (NiTi) shape memory alloys (SMA) can reversibly undergo a diffusion-less solid-to-solid phase transformation among the martensite phase (monoclinic), austenite phase (cubic), and R-phase (rhombohedral). The Young's modulus of the high-temperature austenite phase is usually larger than that of the low-temperature martensite phase [14]. To change the resonant frequency of a ME sensor, Röbisch et al. [15] proposed harnessing the reversible and gradual change in the Young's modulus of NiTi SMA substrates [15]. The entire $2.5 \times$ $15 \mathrm{~mm}$ SMA/ME composite $(1 \mu \mathrm{m} \mathrm{AlN} / 2 \mu \mathrm{m} \mathrm{FeCoSiB} / 50 \mu \mathrm{m}$ $\mathrm{NiTi}$ ) was annealed at $450{ }^{\circ} \mathrm{C}$ for $30 \mathrm{~min}$, to crystallize the NiTi layer. Progressive heating and cooling of this $\mathrm{AlN} / \mathrm{FeCoSiB} / \mathrm{NiTi}$ cantilever induced the reversible phase transformation in the SMA, resulting in a mechanical resonant frequency shift $(\Delta f)$ of $12 \%$. Below room temperature, at $T=20^{\circ} \mathrm{C}$, the SMA was in the martensite phase with $f_{\text {martensite }}=332 \mathrm{~Hz}$. Heating the SMA to 
$T=130{ }^{\circ} \mathrm{C}$ induced the phase transformation to the austenite phase with $f_{\text {austenite }}=351 \mathrm{~Hz}$. Finally, cooling the SMA to $T=$ $64{ }^{\circ} \mathrm{C}$ induced another transition to the R-phase with a corresponding change in the resonant frequency to $f_{\mathrm{R} \text {-phase }}=312 \mathrm{~Hz}$ [15]. Although varying the temperature was used to experimentally induce the phase transformation in this study, one could also control this transformation through the application of stress.

The martensitic transformation temperatures and fatigue stability of NiTi-based SMAs can be tuned for the desired application by alloying with elements such as $\mathrm{Pt}, \mathrm{Au}, \mathrm{Cu}, \mathrm{Hf}$, Co, and $\mathrm{Pd}[16,17,18,19]$. In this manuscript, the alloy $\mathrm{Ti}_{50} \mathrm{Ni}_{35} \mathrm{Cu}_{15}$ is investigated because previously it was identified as an ultralow fatigue SMA material, able to undergo this phase transformation for millions of cycles, reversibly [16, 20]. The sputter deposition process we use results in thin-film amorphous SMAs; therefore, all samples must be crystallized at high temperatures $\left(450-700{ }^{\circ} \mathrm{C}\right)$ to enable the martensitic phase transformation [21]. The annealing process has a significant impact on the surface morphology of crystalline $\mathrm{TiNiCu}$ films, where higher postsputter annealing temperatures increase the surface roughness and grain size of $\mathrm{TiNiCu}$ [22]. The integration of high-quality AlN piezoelectric and TiNiCu SMA thin films is the key task for the future development of a ME sensor with a tunable resonant frequency. The major aim of the presented work was to evaluate the influence of the annealing $\mathrm{TiNiCu}$ on the piezoelectric performance of AlN in fabricated $\mathrm{AlN} / \mathrm{Pt} / \mathrm{Ta} / \mathrm{TiNiCu} / \mathrm{Ta} / \mathrm{Si} / \mathrm{FeCoSiB}$ composites.

\section{Results and discussion}

\section{Analytical calculation of resonant frequency}

Mechanical resonant frequencies are well studied for cantilever systems composed of a substrate and a thin film [15, 23, 24]. The theory and Matlab code presented by Zannon et al. [23] are adapted here to calculate the resonant frequency of a freestanding cantilever beam composed of three mechanically coupled thin-film layers (ME/NiTi/Si). The thick Si and NiTi substrates will dominate the elastic properties of the vibration; therefore, the contributions of the adhesion and electrode layers are neglected. The ME mechanical properties $\left(E_{\mathrm{ME}}\right.$ and $\rho_{\mathrm{ME}}$ ) are estimated in Eqs. (S1) and (S2) (Supplementary material I) using the thickness weighted average of the piezoelectric $(2 \mu \mathrm{m} \mathrm{AlN})$ and magnetostrictive $(2 \mu \mathrm{m} \mathrm{FeCoSiB})$ functional layers. Adding additional thin-film material layers to the composite will shift the center of mass $\left(y_{\mathrm{cm}}\right)$ and inertia $\left(I_{\mathrm{x}}\right)$ of the beam layers which can be calculated for using Eqs. (S3)-(S6) (Supplementary material I). Eq. (1) shows that the resonant frequency is dependent on the geometrical dimensions of the cantilever: width $(w)$, length $(L)$, and thickness $\left(t_{\mathrm{x}}\right)$, as well as Young's modulus $\left(E_{\mathrm{x}}\right)$, density $\left(\rho_{\mathrm{x}}\right)$, moment of inertia $\left(I_{\mathrm{x}}\right)$, and in-plane surface area $\left(A_{\mathrm{x}}\right)$ of each material layer $(\mathrm{x}=\mathrm{ME}, \mathrm{NiTi}, \mathrm{Si}) . \lambda$ is an integration constant determined by the boundary conditions for the first bending mode of a cantilever beam $(\lambda=1.875)$ [10].

$$
f_{\mathrm{r}}=\frac{1}{2 \pi} \times \frac{\lambda^{2}}{L^{2}} \times \sqrt{\frac{\left(E_{\mathrm{ME}} I_{\mathrm{ME}}\right)+\left(E_{\mathrm{NiTi}} I_{\mathrm{NiTi}}\right)+\left(E_{\mathrm{Si}} I_{\mathrm{Si}}\right)}{\left(\rho_{\mathrm{ME}} A_{\mathrm{ME}}\right)+\left(\rho_{\mathrm{NiTi}} A_{\mathrm{NiTi}}\right)+\left(\rho_{\mathrm{Si}} A_{\mathrm{Si}}\right)}}
$$

The largest Young's modulus difference for NiTi occurs between the martensite phase $\left(E_{\text {Martensite }}=28-41 \mathrm{GPa}\right)$ and austenite phase $\left(E_{\text {Austenite }}=41-83 \mathrm{GPa}\right.$ ) [25]. Therefore, the maximum $\Delta f$ will occur when there is a full transformation from martensite to austenite, as shown in Eq. (2).

$$
\Delta f=\left(\left(f_{\text {austenite }}-f_{\text {martensite }}\right) / f_{\text {austenite }}\right) \times 100
$$

The analytical calculations presented in this article use the standard literature values of sputtered thin-film binary NiTi [14] to generalize the resonant frequency calculation for other SMA (i.e., TiNiCu, TiNiCuCo, NiTiPd, and NiTiPt) because the mechanical properties of thin-film NiTi $[21,25]$ are similar to those of $\mathrm{TiNiCu}$ [20]. A summary of all material properties used in the following calculations and experiments is shown in Table I.

ME sensors fabricated onto smooth $\mathrm{Si}$ and polycrystalline Si substrates are known to have large mechanical quality factors [26]. The mechanical resonant frequency of both the martensite and austenite phase is evaluated as a function of $\mathrm{NiTi}$ thickness on $350 \mu$ and $100 \mu$ m thick Si substrates in Figs. 1(a) and $1(\mathrm{~b})$, respectively. As the NiTi thicknesses increases, $\Delta f$ also increases, due to a larger volume of material undergoing the phase transformation. However, due to the thick Si layers, only a small shift is theoretically achievable $\left(\Delta f_{\mathrm{Si}}=350 \mu \mathrm{m}=\right.$ $0.1-2 \%)$ and $\left(\Delta f_{\mathrm{Si}}=100 \mu \mathrm{m}=0.3-5.4 \%\right)$. As shown in Fig. 1(c), when the $\mathrm{Si}$ substrate is eliminated, $\Delta f$ can be significantly enhanced $\left(\Delta f_{\text {freestanding }}=7.6-28.3 \%\right)$. Without the Si substrate present, one must consider if the neutral plane $\left[y_{\mathrm{cm}}\right.$, Eq. (S3)] were to lie within the AlN layer in the ME stack, then the sensor could lose its sensitivity due to a balance in compressive and tensile stresses, causing a loss of polarization of AlN [27]. This would likely prevent the ME effect and must be considered when ME composites are fabricated onto freestanding SMA substrates.

The validity of the analytical calculations was checked by obtaining an experimental resonant frequency measurement on a fabricated $(2 \mu \mathrm{m}$ AlN/5.1 $\mu \mathrm{m}$ TiNiCu/350 $\mu \mathrm{m} \mathrm{Si} / 2 \mu \mathrm{m}$ FeCoSiB) ME composite at room temperature. Analytical calculations predicted a resonant frequency of $768 \mathrm{~Hz}$ in the martensite phase and $772 \mathrm{~Hz}$ in the austenite phase for a $2.5 \times$ 25-mm cantilever ME composite of similar thicknesses. The experimental resonant frequency $\left(f_{\text {experiment }}=771 \mathrm{~Hz}\right)$ is in close agreement with the calculated resonant frequency, as 
TABLE I: Mechanical properties ME/SMA/Si composite used in analytical calculations.

\begin{tabular}{|c|c|c|c|c|c|c|}
\hline Material & $\mathrm{NiTi}[14]$ & TiNiCu [22] & (100) silicon [40] & (002) AIN [15] & $\mathrm{FeCoSiB}[15]$ & ME layer \\
\hline Thickness & Varied: 1-80 $\mu \mathrm{m}$ & Not used in calculation & Varied: $0,100,350 \mu \mathrm{m}$ & $2 \mu \mathrm{m}$ & $2 \mu \mathrm{m}$ & $4 \mu \mathrm{m}$ \\
\hline Young's modulus & $\begin{array}{l}E_{\text {Martensite }}: 41 \mathrm{GPa} \\
E_{\text {Austenite }}: 83 \mathrm{GPa}\end{array}$ & $E_{\text {Austenite: }} 78 \mathrm{GPa}$ & (100) Si: $169 \mathrm{GPa}$ & $310 \mathrm{GPa}$ & $150 \mathrm{GPa}$ & $230 \mathrm{GPa}$ \\
\hline Density & $6450 \mathrm{~kg} / \mathrm{m}^{3}$ & $6500 \mathrm{~kg} / \mathrm{m}^{3}$ & $2330 \mathrm{~kg} / \mathrm{m}^{3}$ & $3300 \mathrm{~kg} / \mathrm{m}^{3}$ & $7250 \mathrm{~kg} / \mathrm{m}^{3}$ & $5275 \mathrm{~kg} / \mathrm{m}^{3}$ \\
\hline
\end{tabular}

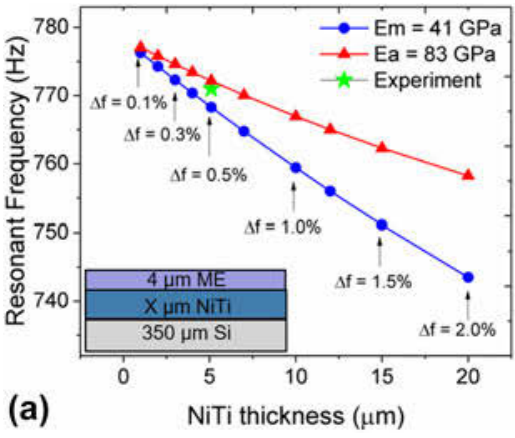

Figure 1: Analytical calculation demonstrating resonant frequency dependence on NiTi thickness on (a) 350- $\mu \mathrm{m}-$-, (b) 100- $\mu \mathrm{m}-$, and (c) 0 - $\mu \mathrm{m}$-thick Si substrates. The largest shift in resonant frequency $(\Delta f)$ occurs when there is a full phase transformation from martensite $\left(E_{\mathrm{m}}=E_{\text {martensite }}=41 \mathrm{GPa}\right)$ to austenite $\left(E_{\mathrm{a}}=E_{\text {austenite }}\right.$ $=83 \mathrm{GPa}$ ).

indicated by the green star in Fig. 1(a). These results are further discussed in the Supplementary material I.

\section{SMA ME sensor fabrication}

As depicted in Fig. 2, $\mathrm{Pt} / \mathrm{Ta} / \mathrm{AlN} / \mathrm{Pt} / \mathrm{Ta} / \mathrm{TiNiCu} / \mathrm{Ta} / \mathrm{Si} / \mathrm{Ta} /$ $\mathrm{FeCoSiB} / \mathrm{Ta}$ composites were deposited via magnetron sputtering (Von Ardenne CS 730S) and structured through a combination photolithography (Karl Suss MA6), and wet and dry etching techniques. Starting with a $350-\mu \mathrm{m}$ thick double-side polished (100) Si wafer [Fig. 2(a)], an adhesion layer (10 nm $\mathrm{Ta})$ and amorphous SMA film $\left(5.1 \mu \mathrm{m} \mathrm{Ti}_{55} \mathrm{Ni}_{30} \mathrm{Cu}_{15}\right)$ are deposited [Fig. 2(b)]. Next, the piezoelectric component is formed into a parallel plate capacitor configuration through deposition of the adhesion layer $(10 \mathrm{~nm} \mathrm{Ta})$, the bottom electrode (120 nm (111) Pt) [Fig. 2(c)], piezoelectric layer (2 $\mu \mathrm{m}$ AlN) [Fig. 2(d)], another adhesion layer (10 nm Ta), and the top electrode [120 nm (111) Pt] [Fig. 2(e)]. A (111) Pt orientation for the bottom electrode is critical to promote $c$-axis (002) AlN texture during the low-temperature pulsed DC reactive sputtering process used here [28]. The top electrode and AlN layer are structured using ion beam etching (IBEOxford Instruments Ionfab $300 \mathrm{IBE})$, and a wet etchant (85 wt\% $\mathrm{H}_{3} \mathrm{PO}_{4}, 80{ }^{\circ} \mathrm{C}$ ) [28], respectively. Finally, the deposition of the amorphous phase magnetostrictive layer, sandwiched between an adhesion layer and protection layer (10 nm Ta/2 $\mu \mathrm{m} \mathrm{FeCoSiB/10} \mathrm{nm} \mathrm{Ta),} \mathrm{is} \mathrm{executed} \mathrm{via} \mathrm{RF}$ sputtering on the backside of the $\mathrm{Si}$ wafer and structured through photolithography and IBE as shown in Fig. 2(f). The annealing step required to crystallize the SMA must occur before magnetostrictive deposition because amorphous FeCo$\mathrm{SiB}$ is known to crystallize at temperatures above $300{ }^{\circ} \mathrm{C}[7,29]$. An advantage to putting $\mathrm{FeCoSiB}$ on the backside is the $\mathrm{Si}$ substrate is providing a smooth surface for the deposition of FeCoSiB because previously it was shown to significantly improve the soft magnetic properties [30,31]. The cross section of the fabricated device is shown in Fig. 2(g). The specific sputter parameters (pressure, power, Ar flow, etc.) of each material layer in the composite are given in Table SI (Supplementary material II).

Polycrystalline sputtered $\mathrm{AlN}$ is able to withstand annealing temperatures of up to $1350{ }^{\circ} \mathrm{C}$ [32]. The workflow offers two possibilities: crystallization of $\mathrm{TiNiCu}$ at $700{ }^{\circ} \mathrm{C}$ for $15 \mathrm{~min}$ by rapid thermal annealing (RTA, CreaTec Fischer and Co. $\mathrm{GmBh}$ ) (i) before or (ii) after deposition of AlN, as reflected in steps (b) and (e) in Fig. 2. The annealing step is the most critical part of the process flow because it will set the SMA's microstructure which ultimately will determine the SMA's thermal and mechanical properties. In addition, the annealing temperature will control the martensitic transformation temperatures of the SMA [21]. We only investigated an annealing temperature of $700{ }^{\circ} \mathrm{C}$ in this article; however, temperatures between 450 and $800{ }^{\circ} \mathrm{C}$ would be suitable for most NiTi-based SMA materials.

Figure 3(a) shows a differential scanning calorimetry (DSC Netzsch 204F1Phoenix) measurement of a $20-\mu$ m thick TiNiCu film after annealing at $700{ }^{\circ} \mathrm{C}$ for $15 \mathrm{~min}$. The austenite and martensite transformation temperatures (i.e., $A_{\mathrm{s}}=63.5^{\circ} \mathrm{C}, A_{\mathrm{f}}$ $=68.8{ }^{\circ} \mathrm{C}, M_{\mathrm{s}}=52.4{ }^{\circ} \mathrm{C}$, and $\left.M_{\mathrm{f}}=50.3{ }^{\circ} \mathrm{C}\right)$ occur at 


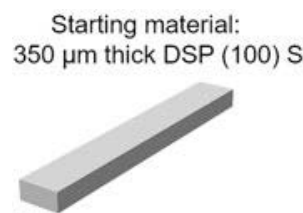

(a)

Deposit and structure $2 \mu \mathrm{m}(002)$ AIN

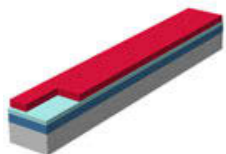

(d)

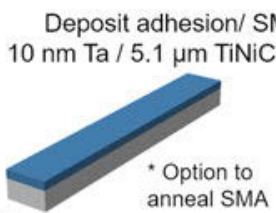

(b)

Deposit and structure top electrode $10 \mathrm{~nm} \mathrm{Ta} \mathrm{/}$ $120 \mathrm{~nm}$ Pt

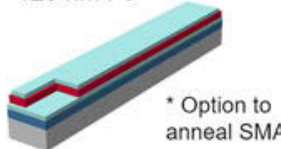

(e)

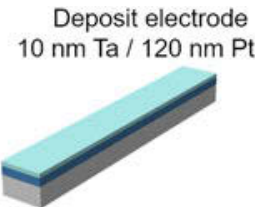

(c)

Deposit and structure $10 \mathrm{~nm} \mathrm{Ta} / 2 \mu \mathrm{m}$ $\mathrm{FeCoSiB} / 10 \mathrm{~nm}$ Ta

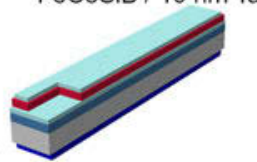

(f)

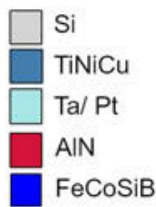

2D Cross Section

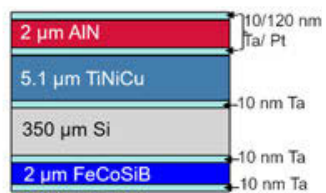

(g)

Figure 2: Process flow for SMA/ME magnetoelectric composite fabrication. (a) Starting material 350- $\mu$ m-thick Si. (b) Sputter deposition of amorphous 5- $\mu$ m-thick TiNiCu*. (c) Deposit bottom electrode $120 \mathrm{~nm}(111) \mathrm{Pt}$. (d) Low-temperature pulsed DC reactive sputtering of piezoelectric layer $2 \mu \mathrm{m}(002) \mathrm{AlN}$, structured via wet etching with $\mathrm{H}_{3} \mathrm{PO} \mathrm{O}_{4}$. (e) Deposit top electrode $120 \mathrm{~nm}$ (111) Pt, structured via ion beam etching*. (f) Deposit magnetostrictive layer $2 \mu \mathrm{m}$ FeCoSiB, and structured via ion beam etching. (g) $2 \mathrm{D}$ cross section of final fabricated device. *Rapid thermal anneal (RTA) heat treatment to crystallize the SMA can occur either before step (b) or after step (e).
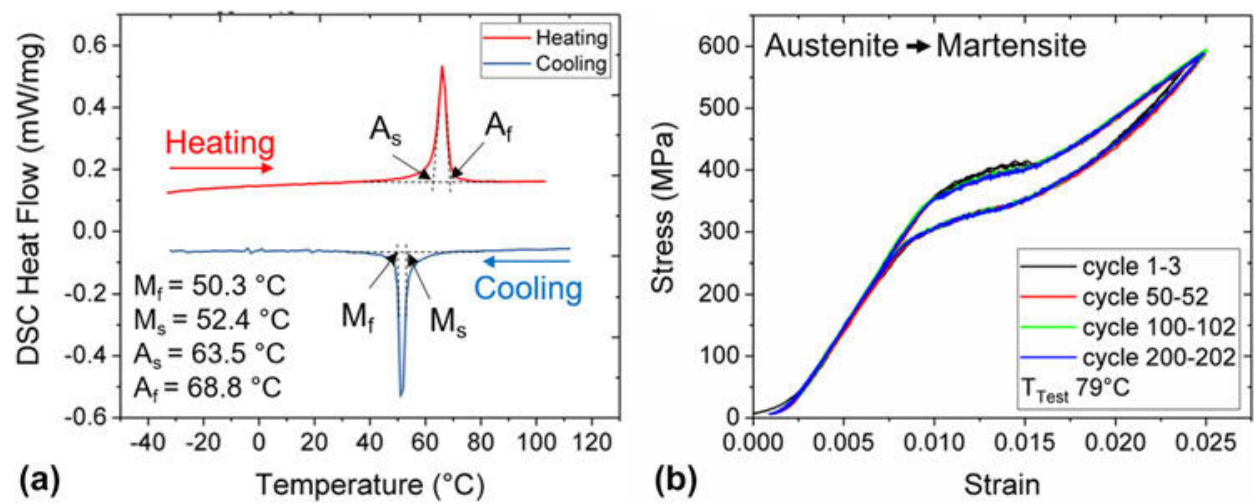

Figure 3: Shape memory alloy characterization of freestanding TiNiCu film annealed to $700{ }^{\circ} \mathrm{C}$ for 15 min. (a) Differential scanning calorimetry curves show the austenite and martensite transformation temperatures of the sample. (b) Exemplary tensile testing plot of a TiNiCu dogbone reversibly stretching to a strain of 0.025, 200 times with no observable fatigue.

a moderate temperature suitable for ME sensor operations. These transformation temperature measurements are in good agreement with temperature-dependent XRD measurements on the fabricated composites, discussed in the Supplementary material III. A tensile testing (Zwick Roell Z.05) plot of TiNiCu after annealing is shown in Fig. 3(b). When TiNiCu is pulled to an elongation of $2.5 \%$ (strain $=0.0025$ ) for 200 cycles, there was very little observed structural and functional fatigue demonstrated in the SMA's hysteresis loop. This is also in agreement with the literature where previously $\mathrm{TiNiCu}$ thin films of similar composition were found to be ultralow fatigue materials, reversibly undergoing the phase transformation $10^{7}$ times with minimal functional fatigue demonstrated in the hysteresis loop [16].

\section{Piezoelectric characterization of (002) AIN}

$c$-axis (002) AlN polycrystalline thin-film growth is known to be highly dependent on the underlying substrate surface roughness $[28,33]$. Variations in the structural and piezoelectric properties are evaluated for sputtered polycrystalline AlN onto (111) Pt seed layers on three substrates: Si (Sample 1), already crystalline $\mathrm{TiNiCu}$ on $\mathrm{Si}$ (Sample 2), and amorphous TiNiCu on Si (Sample 3). Sample 3 must be annealed after AlN deposition to crystallize the underlying TiNiCu film (Sample 3: annealed). To provide a complete comparison, Sample 1 and Sample 2 were also characterized after annealing the composites (i.e., Sample 1: annealed and Sample 2: annealed).

Nanoscale imaging of the surface topography (root mean squared-RMS) with atomic force microscopy (AFM) in tapping mode was conducted on at least three different locations on all samples. These surface roughness measurements were then correlated with the structural crystallinity of AlN, revealed by the full width at half maximum (FWHM) XRD rocking curve ( $\omega$ scans) about the (002) AlN peak $(2 \theta=$ $\sim 36.7^{\circ}$ ). A narrow FWHM typically indicates a highly textured 
(002) AlN with columnar $c$-axis growth, thus better quality AlN film and higher $d_{33, \mathrm{f}}$ [34]. Figure 4(a) shows a $1-\mu \mathrm{m} \times 1-\mu \mathrm{m}$ AFM image of Sample 1: as-deposited (reference sample), (002) AlN on smooth Si substrate with a low surface roughness of RMS $=1.29 \mathrm{~nm} \pm 0.39 \mathrm{~nm}$ and FWHM $=2.39^{\circ}$. Fig. $4(\mathrm{~b})$ shows AlN deposited onto already crystalline TiNiCu (Sample 2: as-deposited) has a larger surface roughness RMS = $3.57 \mathrm{~nm} \pm 0.23 \mathrm{~nm}$ and larger FWHM $=2.74^{\circ}$. As shown in Fig. 4(c), the lowest surface roughness is obtained when AlN is deposited onto an amorphous $\mathrm{TiNiCu}$ film of $\mathrm{RMS}=$ $0.86 \mathrm{~nm} \pm 0.26 \mathrm{~nm}$ with the narrowest FWHM $=1.72^{\circ}$ (Sample 3: as deposited). The AFM map in Fig. 4(d) shows that upon annealing the AlN/amorphous $\mathrm{TiNiCu} / \mathrm{Si}$ composite to $700{ }^{\circ} \mathrm{C}$ (Sample 3: annealed), the surface roughness slightly increased from $0.86 \mathrm{~nm} \pm 0.26$ to $1.00 \mathrm{~nm} \pm$ $0.14 \mathrm{~nm}$, which only corresponded to a slight increase in the FWHM from $1.72^{\circ}$ to $1.79^{\circ}$. The rocking curve measurements used to calculate the FWHM value for all samples are shown in Fig. 4(e).

The effective longitudinal piezoelectric coefficient $\left(d_{33, \mathrm{f}} \pm\right.$ standard deviation) was determined through standard double beam laser interferometry (aixACCT Systems, aixDBLI) measurements $[35,36]$. DBLI polarization and displacement curves were compared for Samples 1-2 in the as-deposited state and Sample 3 after annealing. Polarization measurements in Fig. 5(a) demonstrate Sample 1 has an average $d_{33 \text {,f }}$ coefficient of $5.8 \mathrm{pm} / \mathrm{V} \pm 0.3 \mathrm{pm} / \mathrm{V}$, on par with the state-of-the-art values reported for low-temperature sputtered AlN [28]. Sample 1 also displays a typical linear polarization behavior with similar characteristics to AlN sputtered onto other electrodes ( $\mathrm{Ti}, \mathrm{Pt}$, and $\mathrm{Al}$ ) on $\mathrm{Si}$ substrates [33]. The $d_{33, \mathrm{f}}$ value is found to slightly improve when AlN is sputtered onto (111) $\mathrm{Pt}$ on both amorphous and crystalline TiNiCu thin films on $\mathrm{Si}$ substrates. Despite the large surface roughness in Sample 2, the typical linear polarization behavior of AlN was observed in Fig. 5(b), with a high longitudinal piezoelectric coefficient $d_{33, \mathrm{f}}$ $=6.0 \mathrm{pm} / \mathrm{V} \pm 0.3 \mathrm{pm} / \mathrm{V}$. A linear polarization loop and an even larger $d_{33, \mathrm{f}}$ coefficient was obtained when AlN was deposited onto amorphous TiNICu for Sample 3 as-deposited $\left(d_{33, \mathrm{f}}=6.3 \mathrm{pm} / \mathrm{V} \pm 0.2 \mathrm{pm} / \mathrm{V}\right)$. However, Fig. 5(c) shows the annealing step results in an open polarization loop for Sample 3-annealed. This indicates the AlN layer in Sample 3-annealed has a higher conductivity and higher resistive losses than the other samples. A summary of all DBLI measurements are given in Table SII (Supplementary material IV). The $d_{33 \text {,f }}$ and polarization curves of all samples in the as-deposited state and after annealing state are shown in Fig. S4 (Supplementary material IV). These results prompted investigation of the interfaces to correlate microstructure changes to the electrical and structural properties of sputtered AlN. Table II shows a summary of all investigated piezoelectric properties of each sample in both the as-deposited state, and after annealing at $700{ }^{\circ} \mathrm{C}$ for $15 \mathrm{~min}$

\section{Microstructural characterization of AIN on crystallized and amorphous TiNiCu}

The chemical integrity, surface morphology, and interface study of the composites fabricated by the two different approaches are analyzed with STEM Z-contrast images and energy-dispersive X-ray spectroscopy (EDS). A cross-section image of Sample 2 is shown in Fig. 6(a). The crystalline texture of the AlN film was analyzed by electron diffraction (ED) experiments which show a $5^{\circ}$ out-of-plane tilt for the $c$-axis columnar texture of the (002) AlN film depicted in Fig. 6(b). Annealing the TiNiCu before AlN deposition results in a polycrystalline structure with grains sizes of $\mathrm{TiNiCu}$ in the range of 100-400 nm and of different stoichiometry apparent from the brighter and darker $Z$-contrast. To link the observed differences in $Z$-contrast and morphology in the TiNiCu film to the chemical composition, Fig. 6(c) shows the EDS profiles along the interface region (yellow arrow) and quantified according to the stoichiometry at each measured data point.

The dashed black lines differentiate between grains of different $Z$-contrast and grain morphology, especially at the 140 -nm-thick interface region. Following the element profiles from left to right, the high $Z$-contrast grains of TiNiCu yields the targeted composition of $\sim \mathrm{Ti}_{50} \mathrm{Ni}_{35} \mathrm{Cu}_{15}$. However, on entering the first low $\mathrm{Z}$-contrast grain, the amounts of $\mathrm{Ti}$ and $\mathrm{Cu}$ increase, whereas $\mathrm{Ni}$ decreases, yielding an average composition of $\sim \mathrm{Ti}_{66} \mathrm{Ni}_{14} \mathrm{Cu}_{20}$. Close to the interface, the Ni content increases, whereas $\mathrm{Cu}$ decreases, giving a different average composition of $\sim \mathrm{Ti}_{65} \mathrm{Ni}_{31} \mathrm{Cu}_{4}$, followed by separate and distinct layers of $\mathrm{Ta}, \mathrm{Pt}$, and AlN. A detailed characterization of further common precipitates present in $\mathrm{TiNiCu}$ films such as $\mathrm{Ti}_{2} \mathrm{Cu}$ was not performed in this study. However, for an indepth discussion of the $\mathrm{Ti}_{2} \mathrm{Cu}$ role the reader is referred to Dankwort et al. [37]. The heterogeneous variation in $\mathrm{TiNiCu}$ grain stoichiometry would be problematic for reliable $\mathrm{ME}$ sensor operation because the stoichiometry is known to strongly influence the formation enthalpies leading to degeneracy of the transformation temperatures within the film; hence, only partial transformations would be observed on heating to a specific temperature $[20,38]$.

In comparison, the cross-section and ED pattern of the AlN film of Sample 3 are presented in Figs. 6(d) and 6(e) together with the EDS profiles given in Fig. 6(f). The most apparent difference between the two composites is the formation of a $~ 420$-nm-wide diffusion region expanded over the $\mathrm{Ti}^{-}$ enriched and $\mathrm{Cu}$-poor $\mathrm{TiNiCu}$ grains at the interface to the bottom $\mathrm{Ta} / \mathrm{Pt}$ electrode by interdiffusion upon RTA. Further discussion about the envisioned diffusion process can be found 
Sample 1

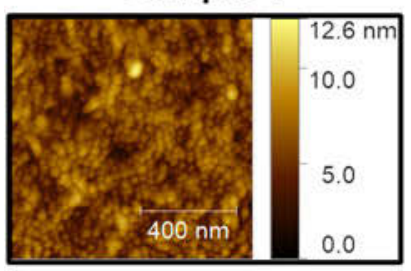

$\mathrm{RMS}=1.29 \mathrm{~nm}, \mathrm{FWHM}=2.39^{\circ}$

(a)

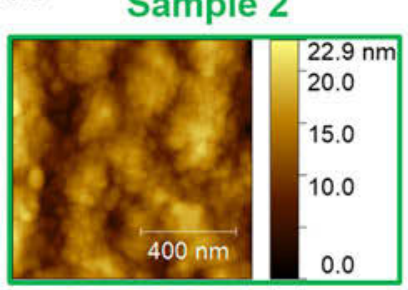

$\mathrm{RMS}=3.57 \mathrm{~nm}, \mathrm{FWHM}=2.74^{\circ}$ (b)
Sample 3

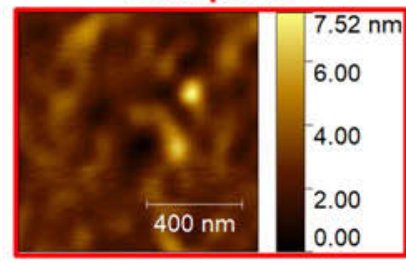

$\mathrm{RMS}=0.86 \mathrm{~nm}, \mathrm{FWHM}=1.72^{\circ}$

(c)

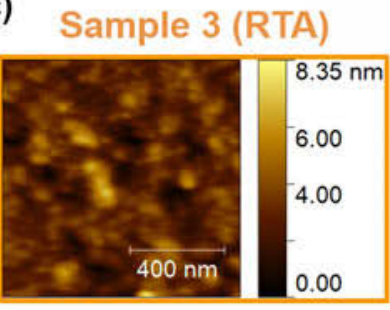

$\mathrm{RMS}=1.00 \mathrm{~nm}, \mathrm{FWHM}=1.79^{\circ}$

(d)

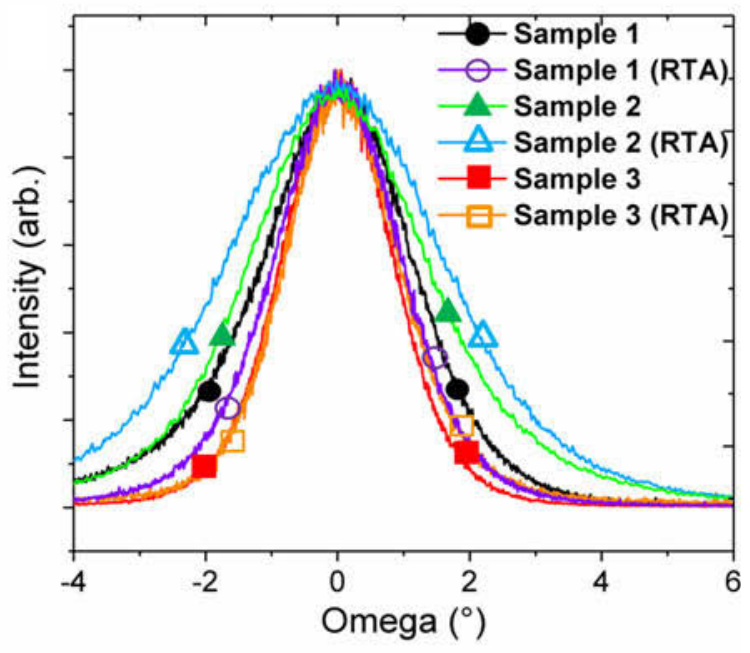

(e)

Figure 4: Structural characterization of (002) AIN grown onto various substrate types. AFM surface roughness measurements. (a) Sample 1: (100) Si (reference sample) (black), (b) Sample 2: already crystalline TiNiCu (green), (c) Sample 3: amorphous TiNiCu (red), and (d) Sample 3 after annealing: amorphous TiNiCu then crystallized (orange). (e) X-ray diffraction rocking curve ( $\omega$ scans) of the (002) AIN peak $\left(2 \theta=\sim 36.7^{\circ}\right)$ and FWHM for each sample shown in (a)-(d).
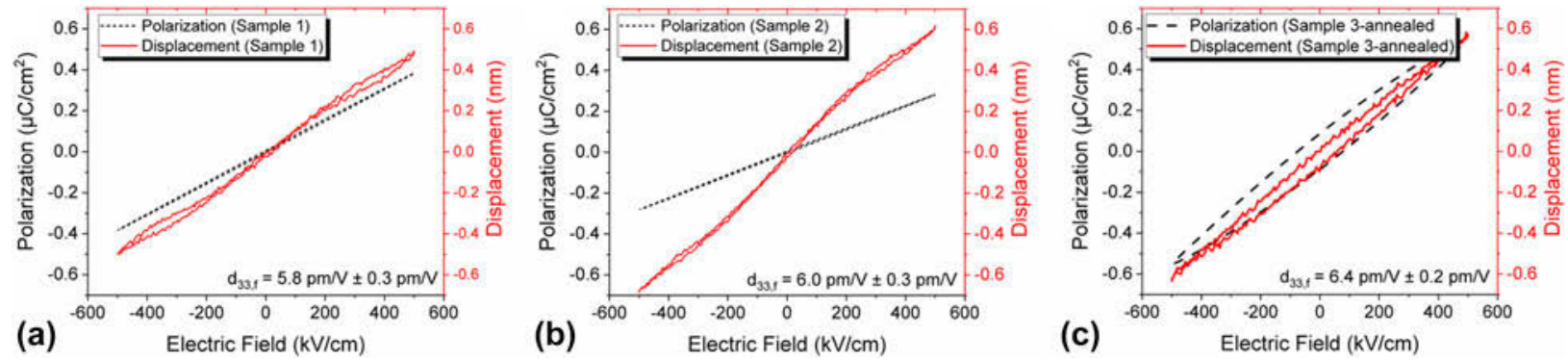

Figure 5: Polarization and displacement curves obtained from DBLI measurements with an applied electric field between $\pm 500 \mathrm{kV} / \mathrm{cm}$. (a) Sample 1: asdeposited, (b) Sample 2: as-deposited, and (c) Sample 3: annealed.

TABLE II: Summary of investigated (002) AIN piezoelectric properties of samples as-deposited and after annealing at $700{ }^{\circ} \mathrm{C}$ for 15 min.

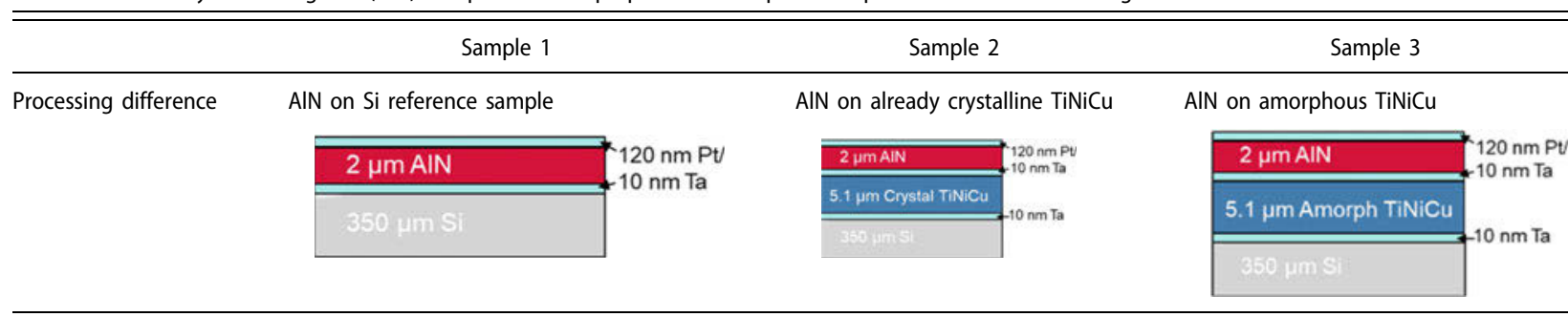

Material property Sample 1: as-deposited Sample 1: annealed Sample 2: as-deposited Sample 2: annealed Sample 3: as-deposited Sample 3: annealed

\begin{tabular}{lcccccc}
\hline DBLI: $d_{33, \mathrm{f}}$ & $5.8 \pm 0.3 \mathrm{pm} / \mathrm{V}$ & $5.9 \pm 0.3 \mathrm{pm} / \mathrm{V}$ & $6.0 \pm 0.3 \mathrm{pm} / \mathrm{V}$ & $6.4 \pm 0.1 \mathrm{pm} / \mathrm{V}$ & $6.3 \pm 0.2 \mathrm{pm} / \mathrm{V}$ & $6.4 \pm 0.2 \mathrm{pm} / \mathrm{V}$ \\
XRD: FWHM & $2.39^{\circ}$ & $2.34^{\circ}$ & $2.74^{\circ}$ & $3.94^{\circ}$ & $1.79^{\circ}$ & $1.72^{\circ}$ \\
AFM: RMS & $1.29 \pm 0.39 \mathrm{~nm}$ & $2.66 \pm 1.12 \mathrm{~nm}$ & $3.57 \pm 0.23 \mathrm{~nm}$ & $4.64 \pm 1.30 \mathrm{~nm}$ & $0.86 \pm 0.26 \mathrm{~nm}$ & $1.00 \pm 0.14 \mathrm{~nm}$ \\
\hline \hline
\end{tabular}

in the Supplementary material V. This Ti-enriched and $\mathrm{Cu}-$ poor interface grain structure $(\sim 340 \mathrm{~nm})$ is evidenced also at the Si substrate/Ta interface. The ED pattern on the AlN film provides evidence of an excellent $c$-axis texture without any misalignment in the analyzed area of the film.
Concerning the stoichiometry of the SMA film, smaller variations in the $Z$-contrast images are observed, and an average composition of $\sim \mathrm{Ti}_{50} \mathrm{Ni}_{33} \mathrm{Cu}_{17}$ was measured by EDS. However, close to the diffusion region, the EDS profiles indicate larger stoichiometric deviance of the $\mathrm{TiNiCu}$ 


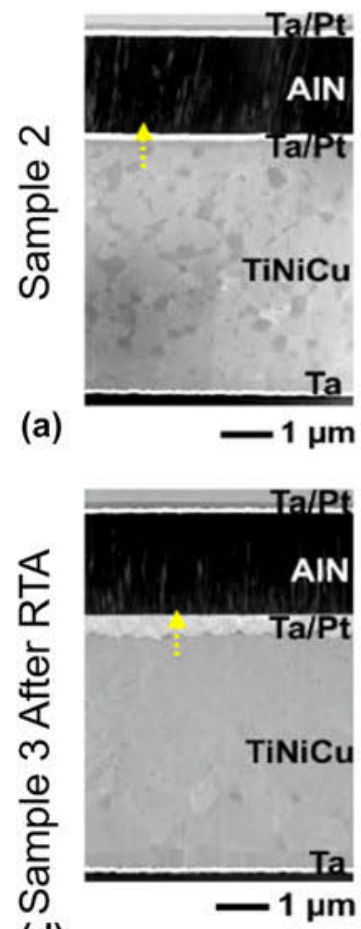

(d)

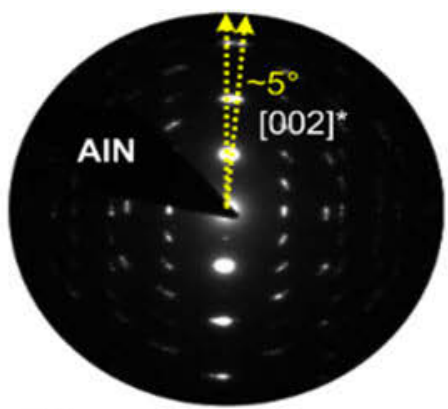

(b)

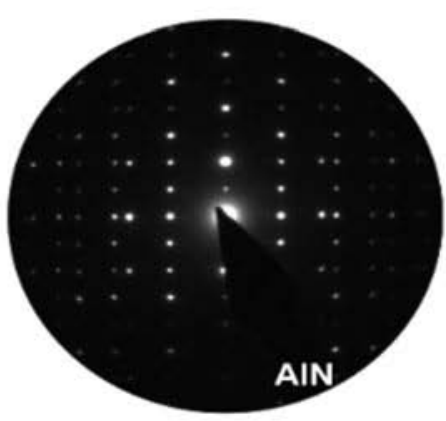

(e)
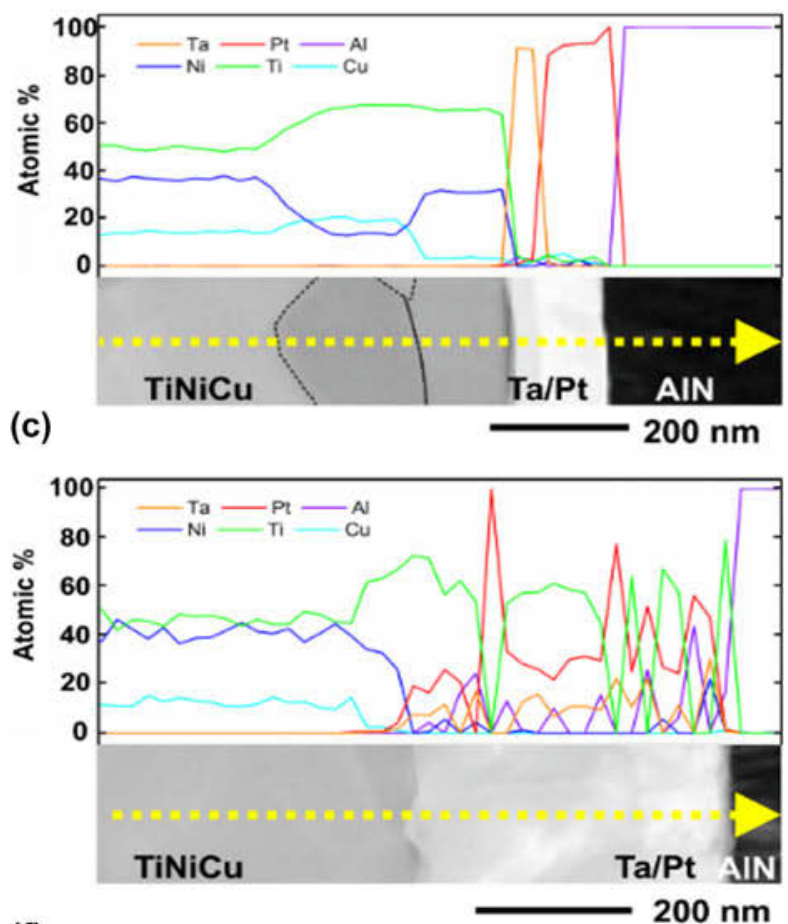

(f)

Figure 6: (a) STEM image of the cross-section through Sample 2. The yellow arrow labels the position of the EDS profile. (b) ED pattern of the AIN film demonstrating partial out-of-plane tilt of $5^{\circ}$ columnar grains. (c) EDS profile showing the quantitative atomic distribution across the interface between AIN and TiNiCu. (d) STEM image of the cross-section of Sample 3 after annealing. (e) ED pattern of the AIN film. (f) EDS profile showing the quantitative atomic distribution across the interface between AIN and TiNiCu.

composition than the average composition. Here, it is assumed that Ti diffused into the Ta/Pt layers, breaking up the electrode structure. As a result, $\mathrm{Ni}(\sim 40$ at.\%) accumulated in the intermediate interface region with respect to the average film stoichiometry. The transformation from the martensite phase (room temperature) into the austenite $\left(120^{\circ} \mathrm{C}\right)$ phase was probed by in situ heating experiments collecting diffraction information at room and high temperature for both samples. The results are discussed in Fig. S5 (Supplementary material V).

\section{Conclusions}

High-quality $c$-axis oriented (002) AlN films were obtained on ultralow fatigue $\mathrm{TiNiCu}$ shape memory alloy thin films on $\mathrm{Si}$ substrates. Analytical calculations demonstrate that a wide range of tunability is possible by incorporating $\mathrm{ME}$ composites onto thinfilm SMA. Variations in the piezoelectric performance of AlN are found to be strongly correlated to the underlying film's surface roughness, grain size, and thickness. While the best crystalline (002) AlN films were obtained on amorphous TiNiCu (Sample 3: As-deposited, $\left.d_{33, \mathrm{f}}=6.3 \mathrm{pm} / \mathrm{V} \pm 0.2 \mathrm{pm} / \mathrm{V}\right)$, annealing the composite to $700{ }^{\circ} \mathrm{C}$ to crystallize the SMA-promoted interdiffusion of $\mathrm{Ti}$ into the $\mathrm{Ta}$ adhesion layer and Pt electrode layer. There was little observed change in the large longitudinal piezoelectric coefficient from the annealing step (Sample 3: annealed, $d_{33, \mathrm{f}}=6.4$ $\mathrm{pm} / \mathrm{V} \pm 0.2 \mathrm{pm} / \mathrm{V}$ ); however, an open polarization loop was observed, which indicates a high leakage current in the AlN film. In the case where $\mathrm{AlN}$ is sputtered onto already crystalline $\mathrm{TiNiCu}$, a large piezoelectric coefficient is obtained (Sample 2: as deposited, $d_{33, \mathrm{f}}=6.0 \mathrm{pm} / \mathrm{V} \pm 0.3 \mathrm{pm} / \mathrm{V}$ ), despite the large surface roughness of crystalline TiNiCu causing a $5^{\circ}$ misalignment in the $c$-axis direction. Furthermore, the expected linear polarization [33] of $\mathrm{AlN}$ is obtained for this sample; therefore, this method is found to be the most promising fabrication route for tunable ME composite applications.

Polycrystalline sputtered AlN will display its best mechanical and electrical performance when deposited onto a substrate with low surface roughness $[28,33]$. Because the structural quality of $\mathrm{TiNiCu}$ is dependent on the annealing conditions of the composite, future studies should consider significantly lower annealing temperatures $\left(\sim 500{ }^{\circ} \mathrm{C}\right)$ because it was reported to reduce the small grain size and surface roughness for $\mathrm{TiNiCu}$ [22]. Another possible solution to reduce the surface roughness of the SMA before AlN deposition is through a chemical-mechanical polish or an electropolishing treatment [39]. Alternatively, these issues could entirely be circumvented if one were to deposit and crystallize the SMA on one side of the silicon wafer followed by the structuring of an AlN/ FeCoSiB inverse bilayer sensor onto the other side of the wafer [30]. 


\section{Methods and materials}

\section{Piezoelectric characterization}

DBLI measurements were performed on all samples in a parallel plate capacitor geometry on an aixACCT Systems aixDBLI tool. Polarization and displacement curves were taken at a minimum of three spots on each samples to generate an average $d_{33, f}$ at each applied voltage (i.e., $10 \mathrm{~V}, 20 \mathrm{~V}, 50 \mathrm{~V}$, and $100 \mathrm{~V})$. The slope of the displacement curves at each applied voltage is used to obtain $d_{33, \text { f }}$.

\section{Structural characterization}

AFM measurements were obtained on an AIST-NP SPM 1000 instrument in noncontact tapping mode were conducted using a $160-\mu \mathrm{m}$-long arrowhead tip [NanoWorld Arrow NC]. XRD (SmartLab $9 \mathrm{~kW}$, Rigaku) $\omega$ rocking curve measurements were performed in a $\omega$ range $\pm 10^{\circ}$ around the (002) AlN peak $(2 \theta=$ $\sim 36^{\circ}$ ) with a step size of $0.02^{\circ}$ and a scan speed of $1^{\circ}$ per min.

\section{Microstructural characterization}

The samples were investigated using transmission electron microscopy operated in scanning (STEM) mode on a Tecnai F30 $\mathrm{G}^{2}$ Twin instrument equipped with a Si/Li-drift detector (EDAX system) for energy-dispersive X-ray spectroscopy (EDS) analysis. The samples have been prepared to electron transparency by the focused ion beam (FIB) method using Gaions and $\mathrm{Pt}$ protection layers during the thinning procedure.

\section{Acknowledgments}

This work was supported by the German Research Foundation (Deutsche Forschungsgemeinschaft, DFG) through the Collaborative Research Centre CRC 1261 Magnetoelectric Sensors: From Composite Materials to Biomagnetic Diagnostics. This material is based on the work supported by the National Science Foundation Graduate Research Fellowship under Grant No. DGE 1840340. The authors thank Prof. Dr. Klaus Rätzke for his assistance in discussing the diffusion processes.

\section{Supplementary material}

To view supplementary material for this article, please visit https://doi.org/10.1557/jmr.2020.106.

\section{References}

1. E. Yarar, S. Fichtner, P. Hayes, A. Piorra, T. Reimer, T. Lisec, P. Frank, B. Wagner, F. Lofink, D. Meyners, and E. Quandt: MEMS-based AlScN resonating energy harvester with solidified powder magnet. J. Microelectromech. Syst. 28, 1019 (2019).
2. C.M. Leung, J. Li, D. Viehland, and X. Zhuang: A review on applications of magnetoelectric composites: From heterostructural uncooled magnetic sensors, energy harvesters to highly efficient power converters. J. Phys. D Appl. Phys. 51, 263002 (2018).

3. C. Tu, Z-Q. Chu, B. Spetzler, P. Hayes, C-Z. Dong, X-F. Liang, H-H. Chen, Y-F. He, Y-Y. Wei, I. Lisenkov, H. Lin, Y-H. Lin, J. McCord, F. Faupel, E. Quandt, and N-X. Sun: Mechanicalresonance-enhanced thin-film magnetoelectric heterostructures for magnetometers, mechanical antennas, tunable RF inductors, and filters. Materials 12, 2259 (2019).

4. G. Srinivasan, S. Priya, and N. Sun: Composite Magnetoelectrics: Materials, Structures, and Applications (Elsevier, Oxford, U.K., 2015).

5. H. Xi, X. Qian, M-C. Lu, L. Mei, S. Rupprecht, Q.X. Yang, and Q.M. Zhang: A room temperature ultrasensitive magnetoelectric susceptometer for quantitative tissue iron detection. Sci. Rep. 6, 29740 (2016).

6. C. Kirchhof, M. Krantz, I. Teliban, R. Jahns, S. Marauska, B. Wagner, R. Knöchel, M. Gerken, D. Meyners, and E. Quandt: Giant magnetoelectric effect in vacuum. Appl. Phys. Lett. 102, 232905 (2013).

7. B. Tong, X. Yang, Z. Guo, K. Li, J. Ouyang, G. Lin, and S. Chen: Preparation and characterization of $\mathrm{AlN} / \mathrm{FeCoSiB}$ magnetoelectric thin film composites. Ceram. Int. 39, 6853 (2013).

8. V. Röbisch, S. Salzer, N.O. Urs, J. Reermann, E. Yarar, A. Piorra, C. Kirchhof, E. Lage, M. Höft, and G.U. Schmidt: Pushing the detection limit of thin film magnetoelectric heterostructures. J. Mater. Res. 32, 1009 (2017).

9. R. Jahns, A. Piorra, E. Lage, C. Kirchhof, D. Meyners, J.L. Gugat, M. Krantz, M. Gerken, R. Knöchel, and E. Quandt: Giant magnetoelectric effect in thin-film composites. J. Am. Ceram. Soc. 96, 1673 (2013).

10. P. Zhao, Z. Zhao, D. Hunter, R. Suchoski, C. Gao, S. Mathews, M. Wuttig, and I. Takeuchi: Fabrication and characterization of all-thin-film magnetoelectric sensors. Appl. Phys. Lett. 94, 243507 (2009).

11. G. Deuschl and Y. Agid: Subthalamic neurostimulation for Parkinson's disease with early fluctuations: Balancing the risks and benefits. Lancet Neurol. 12, 1025 (2013).

12. D.-B. S. for P. D. S. Group: Deep-brain stimulation of the subthalamic nucleus or the pars interna of the globus pallidus in Parkinson's disease. N. Engl. J. Med. 345, 956 (2001).

13. W.M.M. Schuepbach, J. Rau, K. Knudsen, J. Volkmann, P. Krack, L. Timmermann, T.D. Hälbig, H. Hesekamp, S.M. Navarro, N. Meier, D. Falk, M. Mehdorn, S. Paschen, M. Maarouf, M.T. Barbe, G.R. Fink, A. Kupsch, D. Gruber, G-H. Schneider, E. Seigneuret, A. Kistner, P. Chaynes, F. OryMagne, C. Brefel Courbon, J. Vesper, A. Schnitzler, L. Wojtecki, J-L. Houeto, B. Bataille, D. Maltête, P. Damier, S. Raoul, F. Sixel-Doering, D. Hellwig, A. Gharabaghi, R. Krüger, M.O. Pinsker, F. Amtage, J-M. Régis, T. Witjas, S. Thobois, 
P. Mertens, M. Kloss, A. Hartmann, W.H. Oertel, B. Post, H. Speelman, Y. Agid, C. Schade-Brittinger, and G. Deuschl: For the EARLYSTIM study group neurostimulation for Parkinson's disease with early motor complications. N. Engl. J. Med. 368, 610 (2013).

14. Johnson Mattey Medical Components, Nitinol Technical Properties. Available at: https://matthey.com/en/markets/ pharmaceutical-and-medical/medical-device-components/ resource-library/nitinol-technical-properties.

15. V. Röbisch, A. Piorra, R. de Miranda, E. Quandt, and D. Meyners: Frequency-tunable nickel-titanium substrates for magnetoelectric sensors. AIP Adv 8, 125320 (2018).

16. C. Chluba, W. Ge, R.L. de Miranda, J. Strobel, L. Kienle, E. Quandt, and M. Wuttig: Ultralow-fatigue shape memory alloy films. Science 348, 1004 (2015).

17. M. Kohl, D. Dittmann, E. Quandt, and B. Winzek: Thin film shape memory microvalves with adjustable operation temperature. Sens. Actuators, A 83, 214 (2000).

18. R. Vitushinsky, S. Schmitz, and A. Ludwig: Bistable thin-film shape memory actuators for applications in tactile displays. $J$. Microelectromech. Syst. 18, 186 (2008).

19. E. Quandt, C. Halene, H. Holleck, K. Feit, M. Kohl, P. Schloßmacher, A. Skokan, and K.D. Skrobanck: Sputter deposition of TiNi, TiNiPd, and TiPd films displaying the two-way shape-memory effect. Sens. Actuators, A 53, 434 (1996).

20. H. Gu, L. Bumke, C. Chluba, E. Quandt, and R.D. James: Phase engineering and supercompatibility of shape memory alloys. Mater. Today 21, 265 (2018).

21. Y. Fu, W. Huang, H. Du, X. Huang, J. Tan, and X. Gao: Characterization of TiNi shape-memory alloy thin films for MEMS applications. Surf. Coating. Technol. 145, 107 (2001).

22. Y. Fu, H. Du, S. Zhang, and Y. Gu: Stress and surface morphology of TiNiCu thin films: Effect of annealing temperature. Surf. Coating. Technol. 198, 389 (2005).

23. M. Zannon: Free vibration of thin film cantilever beam. Int. J. Eng. Tech. Res. 2, 304 (2014).

24. S. Whitney: Vibrations of cantilever beams: Deflection, frequency, and research uses. Website Apr 23 (1999). Available at: https:// imechanica.org/files/Vibrations\%20of\%20Cantilever\%20Beams\% 20.pdf.

25. P. Šittner, L. Heller, J. Pilch, C. Curfs, T. Alonso, and D. Favier: Young's modulus of austenite and martensite phases in superelastic NiTi wires. J. Mater. Eng. Perform. 23, 2303 (2014).

26. S. Zabel, C. Kirchhof, E. Yarar, D. Meyners, E. Quandt, and F. Faupel: Phase modulated magnetoelectric delta-E effect sensor for sub-nano tesla magnetic fields. Appl. Phys. Lett. 107, 152402 (2015).

27. Y. Hong, L. Sui, M. Zhang, and G. Shi: Theoretical analysis and experimental study of the effect of the neutral plane of a composite piezoelectric cantilever. Energy Convers. Manag. 171, 1020 (2018).

28. E. Yarar, V. Hrkac, C. Zamponi, A. Piorra, L. Kienle, and E. Quandt: Low temperature aluminum nitride thin films for sensory applications. AIP Adv. 6, 75115 (2016).

29. V. Hrkac, E. Lage, G. Köppel, J. Strobel, J. McCord, E. Quandt, D. Meyners, and L. Kienle: Amorphous FeCoSiB for exchange bias coupled and decoupled magnetoelectric multilayer systems: Realstructure and magnetic properties. J. Appl. Phys. 116, 134302 (2014).

30. E. Yarar, S. Salzer, V. Hrkac, A. Piorra, M. Höft, R. Knöchel, L. Kienle, and E. Quandt: Inverse bilayer magnetoelectric thin film sensor. Appl. Phys. Lett. 109, 22901 (2016)

31. A. Piorra, R. Jahns, I. Teliban, J.L. Gugat, M. Gerken, R. Knöchel, and E. Quandt: Magnetoelectric thin film composites with interdigital electrodes. Appl. Phys. Lett. 103, 32902 (2013).

32. K.L. Evans, H.M. Liaw, and J-K. Lin: Method for enhancing aluminum nitride. U.S. Patent No. 5,520,785, 1996.

33. S. Pawar, K. Singh, S. Sharma, A. Pandey, S. Dutta, and D. Kaur: Growth assessment and scrutinize dielectric reliability of $c$-axis oriented insulating AlN thin films in MIM structures for microelectronics applications. Mater. Chem. Phys. 219, 74 (2018).

34. A. Iqbal and F. Mohd-Yasin: Reactive sputtering of aluminum nitride (002) thin films for piezoelectric applications: A review. Sensors 18, 1797 (2018).

35. K. Prume, S. Tiedke, and T. Schmitz-Kempen: Double-beam and four-point. Mikroniek 4, 31 (2010).

36. L. Burianova, C.R. Bowen, M. Prokopova, and M. Sulc: Laser interferometric displacement measurements of multi-layer actuators and PZT ceramics. Ferroelectrics 320, 161 (2005).

37. T. Dankwort, J. Strobel, C. Chluba, W. Ge, V. Duppel, M. Wuttig, E. Quandt, and L. Kienle: Martensite adaption through epitaxial nano transition layers in $\mathrm{TiNiCu}$ shape memory alloys. J. Appl. Crystallogr. 49, 1009 (2016).

38. J. Frenzel, A. Wieczorek, I. Opahle, B. Maaß, R. Drautz, and G. Eggeler: On the effect of alloy composition on martensite start temperatures and latent heats in $\mathrm{Ni}$-Ti-based shape memory alloys. Acta Mater. 90, 213 (2015).

39. M. Pohl, C. Heßing, and J. Frenzel: Electrolytic processing of NiTi shape memory alloys. Mater. Sci. Eng., A 378, 191 (2004).

40. M.A. Hopcroft, W.D. Nix, and T.W. Kenny: What is the Young's modulus of silicon? J. Microelectromech. Syst. 19 (2010). 